\title{
Different Cell Wall Polysaccharides are Responsible for Gravity Resistance in the Upper and the Basal Regions of Azuki Bean Epicotyls
}

\author{
Saho Nakano, Kouichi Soga, Kazuyuki Wakabayashi and Takayuki Hoson \\ Department of Biology and Geosciences, Graduate School of Science, Osaka City University, Sumiyoshi-ku, Osaka \\ 558-8585, Japan
}

\begin{abstract}
Effects of hypergravity on growth and the levels of cell wall polysaccharides were examined along epicotyls of dark-grown azuki bean (Vigna angularis Ohwi et Ohashi cv. Erimowase). Elongation growth occurred only in the upper regions, which was suppressed by hypergravity at $300 \mathrm{G}$. The fresh weight also increased in the upper regions, but hypergravity increased it only slightly in the basal regions. The thickness of epicotyls was increased clearly in the upper regions and slightly in the basal regions by hypergravity. The levels of pectin, hemicellulose-I, and hemicellulose-II per unit length of epicotyl were increased by hypergravity in the upper regions, but not in the basal ones. Also, the levels of xyloglucans were increased by hypergravity only in the upper regions. On the other hand, the levels of cellulose per unit length increased from the apical to the basal regions, and hypergravity further increased the levels in all regions. These results suggest that cellulose, instead of xyloglucans, acts as anti-gravitational polysaccharides in the basal regions. Cellulose and xyloglucans may cooperate in resistance of whole stem organs to the gravitational force.
\end{abstract}

\section{Introduction}

Plants have developed a capacity to resist the gravitational force for survival during evolution on land. Because the cell wall encloses the protoplasts and provides the cells with structural rigidity, it has been assumed that the cell wall plays an important role in plant resistance to gravity. Actually, hypergravity increased the cell wall rigidity in various stem organs (Hoson and Soga, 2003; Hoson et al., 2005). Under true microgravity conditions in space, the cell wall rigidity was decreased oppositely (Hoson et al., 2002; Soga et al., 2002). These results support the principal function of the cell wall in gravity resistance in plants.

The mechanical properties of the cell wall are determined by the chemical nature of cell wall constituents. Hypergravity has been shown to increase the cell wall thickness in various materials. Hypergravity also caused a polymerization of certain matrix polysaccharides, such as xyloglucans in dicotyledonous plants and 1,3;1,4- $\beta$-glucans in monocotyledonous Gramineae plants (Hoson and Soga, 2003). In addition, hypergravity decreased xyloglucan-degrading activity in azuki bean epicotyls (Soga et al., 1999a) and Arabidopsis hypocotyls (Soga et al., 2001) and 1,3;1,4- $\beta$-glucanase activity in coleoptiles and mesocotyls of maize (Soga

Article ID: 072104010

Original paper

Received August 20, 2007

Accepted September 21, 2007

"To whom correspondence should be addressed:

Department of Biology and Geosciences, Graduate School of Science, Osaka City University, Sumiyoshi-ku, Osaka 558-8585, Japan; Tel. /Fax: +81-(0)66605-2577;

E-mail: hoson@sci.osaka-cu.ac.jp et al., 1999b). Thus, xyloglucans and 1,3;1,4- $\beta$-glucans appear to act as anti-gravitational cell wall polysaccharides in stem organs (Hoson and Soga 2003; Hoson et al., 2005). The results obtained in space experiments support this hypothesis (Hoson et al., 2002; Soga et al., 2002). However, the analysis of cell wall changes in response to altered gravity conditions has been limited to the growing regions, and the role of the cell wall in the basal supporting regions has not been clarified yet. In the present study, we examined the effects of hypergravity on growth and the levels of cell wall polysaccharides along epicotyls of dark-grown azuki bean.

\section{Materials and Methods}

\section{Plant material and growth experiments}

Seeds of azuki bean (Vigna angularis Ohwi et Ohashi cv. Erimowase) were soaked in running tap water at $30^{\circ} \mathrm{C}$ for $36 \mathrm{~h}$, and they were allowed to germinate and grow on gauze spread on a plastic dish filled with water at $25^{\circ} \mathrm{C}$ in the dark. After 5 days, seedlings with an epicotyl with about $55 \mathrm{~mm}$ long were selected, and then the hook $(5.5 \mathrm{~mm}$ ) and the following five $10-\mathrm{mm}$ regions (A to E from the top) in epicotyls were marked by India ink. The marked seedlings were exposed to basipetal hypergravity at $300 \mathrm{G}$ with a centrifuge (H-28-F; Kokusan Co., Japan) for $6 \mathrm{~h}$ in the dark. After the incubation, the length of the marked regions was measured using a scale, and then excised. The fresh weight of the excised regions was measured using an electronic balance. The diameter (D) of the excised regions was calculated according to the following equation; $D=2 \sqrt{ }($ fresh weight $/$ length $/ \pi$ ), assuming that the fresh weight reflects the volume of the excised segments. After the measurement, the segments were immediately boiled for $10 \mathrm{~min}$ in methanol and 
then stored in fresh methanol until use. All manipulations were done under dim green light.

\section{Fractionation of cell wall components}

The methanol-fixed samples were rehydrated with deionized water, and the cell wall components were fractionated according to the method of Soga et al. (1999a). Rehydrated segments were homogenized in water with a mortar and a pestle, washed with water, acetone, a methanol : chloroform mixture $(1: 1, \mathrm{v} / \mathrm{v})$, and ethanol. The cell wall material was then treated with 2 units $\mathrm{ml}^{-1}$ porcine pancreatic $\alpha$-amylase (EC 3.2.1.1; type I-A, Sigma, St. Louis, MO, USA) in $50 \mathrm{mM}$ sodium acetate buffer $(\mathrm{pH} 6.5)$ at $37^{\circ} \mathrm{C}$ for $3 \mathrm{~h}$ and then washed with deionized water. After the amylase treatment, pectic substances were extracted from the cell wall materials three times (15 min each) with $50 \mathrm{mM}$ EDTA at $95^{\circ} \mathrm{C}$. Then hemicellulose was successively extracted three times with $4 \%(\mathrm{w} / \mathrm{v}) \mathrm{KOH}$ and $24 \%(\mathrm{w} / \mathrm{v}) \mathrm{KOH}$ containing $0.02 \% \mathrm{NaBH}_{4}$ at $25^{\circ} \mathrm{C}$. The fractions extracted with $4 \%$ and $24 \% \mathrm{KOH}$ were designed as hemicellulose-I (HC-I) and hemicellulose-II (HC-II), respectively. HC-I and HC-II fractions were neutralized with acetic acid and then dialyzed against deionized water. The alkaliinsoluble fraction (cellulose fraction) was washed successively with $0.03 \mathrm{M}$ acetic acid and ethanol, and then dried at $40^{\circ} \mathrm{C}$. The dried cellulose fraction was dissolved in $72 \%$ sulfuric acid for $1 \mathrm{~h}$ at $25^{\circ} \mathrm{C}$, and then diluted with a 29 -fold volume of deionized water. The total sugar content in each fraction was determined by the phenol-sulfuric acid method (Dubois et al., 1956) using glucose as the standard. The amount of xyloglucans in the HC-II fraction was determined by the iodine-staining method (Kooiman, 1960).

\section{Results and Discussion}

In 5-day-old azuki bean epicotyls, elongation growth occurred only in the upper regions (hook, A, and B). Elongation growth of these regions for $6 \mathrm{~h}$ was suppressed by hypergravity at $300 G$ (Fig. 1). At $300 G$, elongation of the upper regions was about $50 \%$ of the $1 G$ control. The fresh weight of the upper regions also increased during $6 \mathrm{~h}$ incubation (Fig. 2). Hypergravity did not clearly affect the fresh weight of these regions. As a result, hypergravity caused significant lateral expansion of the upper regions, as shown by the increase in the thickness (diameter) (Fig. 3). On the other hand, in the basal regions $(\mathrm{C}, \mathrm{D}$, and $\mathrm{E})$ elongation grown did not occur but the fresh weight and the thickness tended to slightly increase by hypergravity. Thus, the pattern of growth was clearly different between the upper three regions and the basal three ones in azuki bean epicotyls.

We examined the effects of hypergravity on the levels of cell wall polysaccharides along azuki bean epicotyls. The cell walls were fractionated into pectin, HC-I, HCII, and cellulose fractions, and polysaccharide levels in each fraction were measured. The levels of pectin, HC-I, or HC-II per unit length of epicotyl did not change

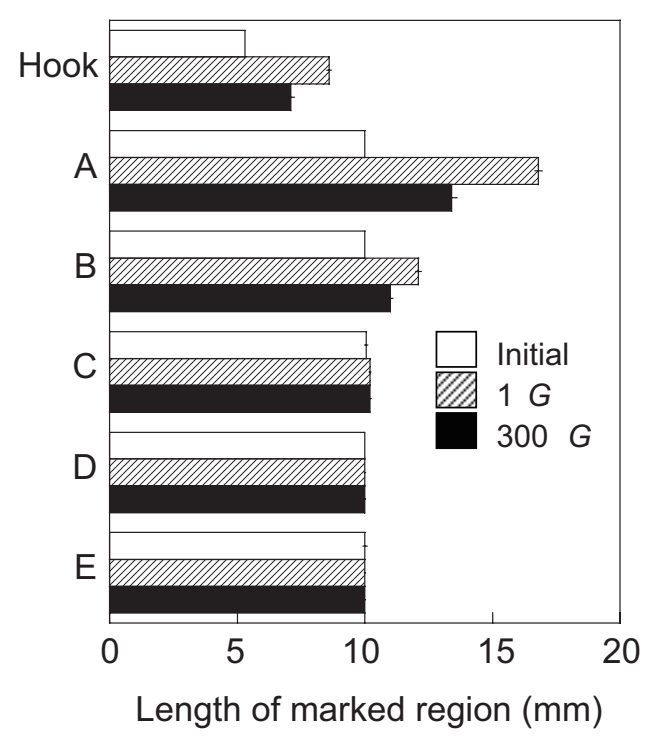

Fig. 1. Effects of hypergravity on elongation growth of azuki bean epicotyls. Seedlings with an epicotyl with about $55 \mathrm{~mm}$ long were selected, and then the hook and the following five 10-mm regions ( $A$ to $E$ from the top) in epicotyls were marked. The seedlings were then grown at $1 \mathrm{G}$ or $300 \mathrm{G}$ conditions for $6 \mathrm{~h}$ in the dark, and the length of the marked regions was measured. Data are means $\pm \operatorname{SE}(n=60)$.

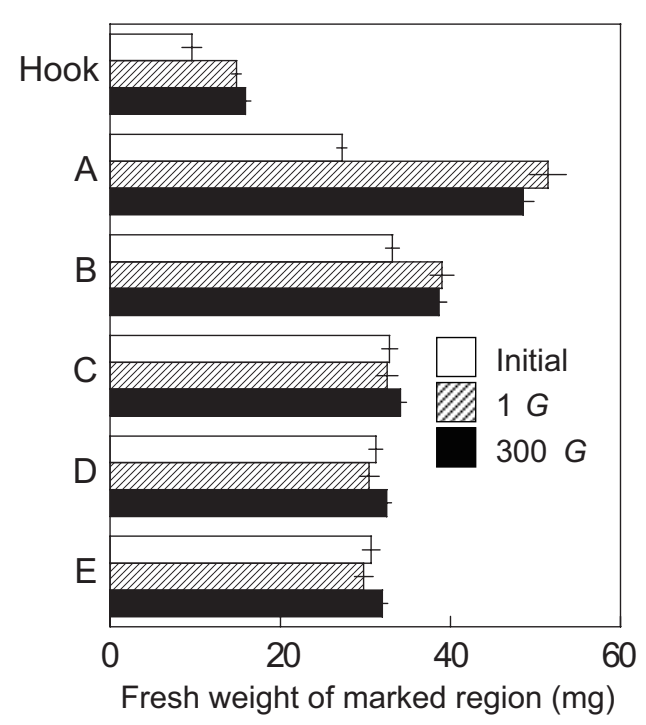

Fig. 2. Effects of hypergravity on the fresh weight of azuki bean epicotyls. Growth conditions are as shown in Fig. 1. Data are means $\pm \operatorname{SE}(n=60)$.

during $6 \mathrm{~h}$ incubation (Fig. 4). Hypergravity significantly increased the levels of these matrix polysaccharides in the upper regions, but not in the basal ones. Xyloglucans are major constituents of HC-II and capable of crosslinking cellulose microfibrils via hydrogen bonds to form the cell wall network. The levels of xyloglucans per unit length decreased from the apical to the basal regions 


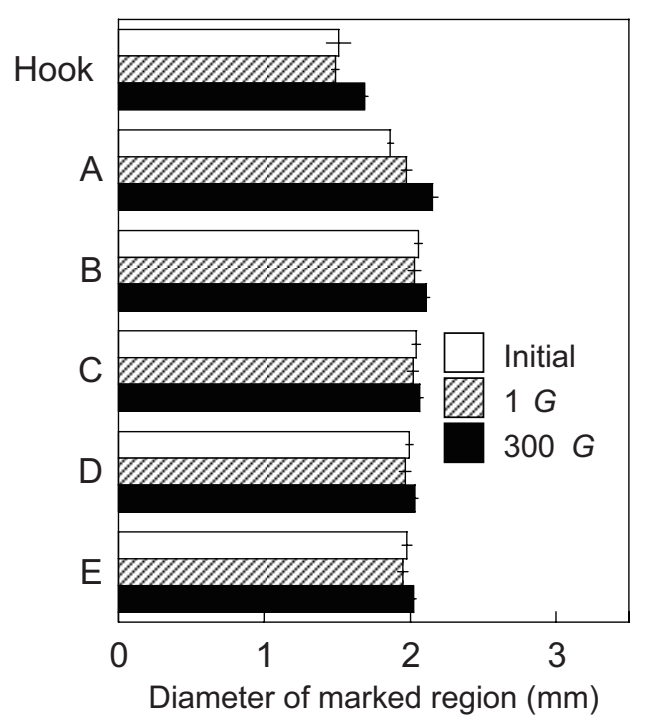

Fig. 3. Effects of hypergravity on the diameter of azuki bean epicotyls. Growth conditions are as shown in Fig. 1. The diameter of each region was calculated with the length and the fresh weight, as described in Materials and Methods. Data are means \pm SE $(n=60)$.

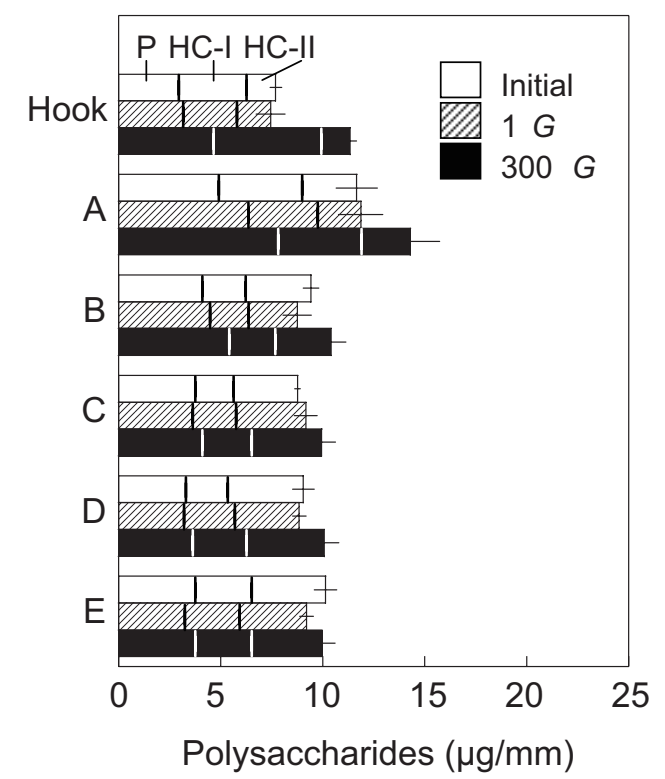

Fig. 4. Effects of hypergravity on levels of matrix polysaccharides. Growth conditions are as shown in Fig. 1. The sugar contents in the pectin, hemicellulose-I, and hemicelluloseII fractions were determined by the phenol-sulfuric acid method. Data are means $\pm \operatorname{SE}(n=3)$.

(Table 1). Hypergravity tended to increase the levels of xyloglucans in the upper regions, but not in the basal ones. It has been shown that xyloglucans act as antigravitational cell wall polysaccharides in dicotyledonous stem organs (Hoson and Soga, 2003; Hoson et al., 2005). The results obtained in the present study, however, suggest that xyloglucans do not always play a principal
Table 1 Effects of hypergravity on xyloglucan levels in the hemicellulose-II fraction.

\begin{tabular}{rccrr}
\hline \multirow{2}{*}{ Region } & \multicolumn{5}{c}{ Xyloglucan content } \\
\cline { 2 - 5 } & Initial & $1 \mathrm{G}$ & $300 \mathrm{G}$ & \\
\hline Hook & 2.9 & 3.3 & 4.1 & $(122)$ \\
$\mathrm{A}$ & 4.8 & 4.2 & 5.2 & $(123)$ \\
$\mathrm{B}$ & 4.5 & 3.8 & 4.6 & $(119)$ \\
$\mathrm{C}$ & 4.0 & 4.2 & 4.1 & $(98)$ \\
D & 4.2 & 3.6 & 4.0 & $(111)$ \\
E & 4.0 & 3.5 & 3.6 & $(103)$ \\
\hline
\end{tabular}

Growth conditions are as shown in Fig. 1. The content of xyloglucans was determined by the iodine-staining method. Numbers in parentheses denote the ratio (\%) of values of $300 \mathrm{G}$ treatment to the $1 \mathrm{G}$ control.

role in gravity resistance in the basal non-growing regions of stem organs.

The levels of cellulose per unit length of epicotyl increased clearly from the apical to the basal regions (Fig. 5). Also, hypergravity significantly increased the cellulose levels in all regions except for region $\mathrm{C}$. Thus, cellulose, instead of xyloglucans, may be responsible for gravity resistance in the basal regions. Cellulose microfibrils are principal components determining the mechanical strength of the cell wall and may contribute to support the whole body weight in the basal regions against the gravitational force. Actually, the levels of cellulose were decreased under microgravity conditions in space (Cowles et al., 1984; Hoson et al., 2002; Soga et al., 2002). In the secondary cell wall, lignin formation was stimulated by hypergravity, suggesting that lignin also play a role in gravity resistance in the basal regions (Nakabayashi et al., 2006; Tamaoki et al., 2006).

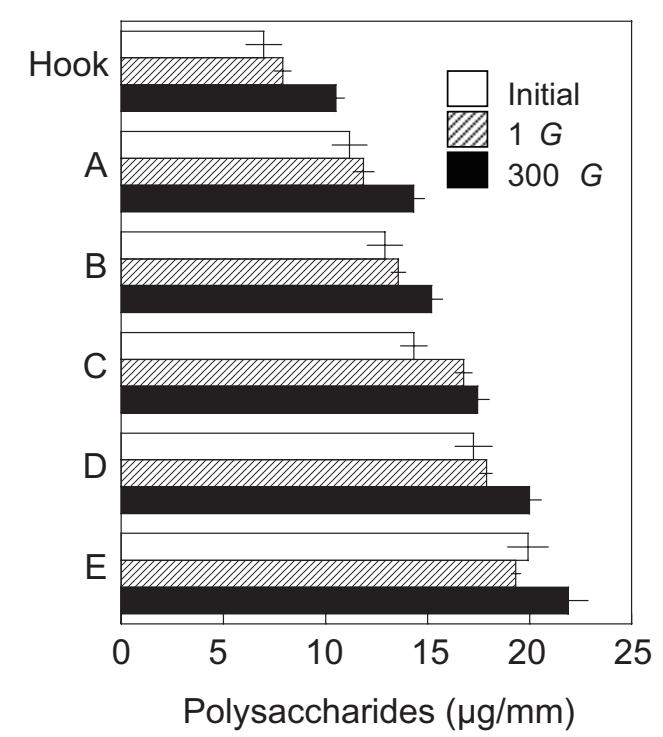

Fig. 5. Effects of hypergravity on cellulose levels. Growth conditions are as shown in Fig. 1. The sugar contents in the cellulose fraction were determined by the phenol-sulfuric acid method. Data are means $\pm \operatorname{SE}(n=3)$. 
Xyloglucans, cellulose, and lignin may closely cooperate in resistance of whole stem organs to the gravitational force.

Recently, it was reported that modifications of xyloglucan metabolism in azuki bean epicotyls under hypergravity conditions were regulated by prompt and differential changes in expressions of xyloglucan endotransglucosylase/hydrolase $(X T H)$ genes (Soga et al., 2007). Out of three XTH genes, the expression of only one gene, which is responsible for xyloglucan breakdown, was down-regulated by hypergravity. Thus, the metabolism of anti-gravitational cell wall polysaccharides may be regulated at the transcriptional level. The analysis of expression of cellulose synthase genes in basal stem regions under different gravity conditions may further clarify the mechanism of gravity resistance in plants.

\section{Acknowledgments}

The present study was supported in part by a Grant for Ground-based Research for Space Utilization from Japan Space Forum.

\section{References}

Cowles, J.R., Scheld, H.W., LeMay, R. and Peterson, C. (1984) Experiments on plants grown in space: growth and lignification in seedlings exposed to eight days of microgravity. Ann. Bot., 54, 33-48.

Dubois, M., Gilles, K.A., Hamilton, J.K., Rebers, P.A. and Smith, F. (1956) Colorimetric method for determination of sugars and related substances. Anal. Chem., 28, 350-356.

Hoson, T., Soga, K., Mori, R., Saiki, M., Nakamura, Y., Wakabayashi, K. and Kamisaka, S. (2002) Stimulation of elongation growth and cell wall loosening in rice coleoptiles under microgravity conditions in space. Plant Cell Physiol., 43, 1067-1071.

Hoson, T. and Soga, K. (2003) New aspects of gravity responses in plant cells. Int. Rev. Cytol., 229, 209-244.

Hoson, T., Saito, Y., Soga, K. and Wakabayashi, K. (2005) Signal perception, transduction, and response in gravity resistance. Another graviresponse in plants. Adv. Space Res., 36, 1196-1202.

Kooiman, P. (1960) A method for the determination of amyloid in plant seeds. Recl. Trav. Chim. Pays-Bas, 79, 675-678.

Nakabayashi, I., Karahara, I., Tamaoki, D., Masuda, K., Wakasugi, T., Yamada, K., Soga, K., Hoson, T. and Kamisaka, S. (2006) Hypergravity stimulus enhances primary xylem development and decreases mechanical properties of secondary cell walls in inflorescence stems of Arabidopsis thaliana. Ann. Bot., 97, 1083-1090.

Soga, K., Wakabayashi, K., Hoson, T. and Kamisaka, S. (1999a) Hypergravity increases the molecular mass of xyloglucans by decreasing xyloglucan-degrading activity in azuki bean epicotyls. Plant Cell Physiol., 40, 581-585.

Soga, K., Harada, K., Wakabayashi, K., Hoson, T. and Kamisaka, S. (1999b) Increased molecular mass of hemicellulosic polysaccharides is involved in growth inhibition of maize coleoptiles and mesocotyls under hypergravity conditions. J. Plant Res., 112, 273-278.

Soga, K., Wakabayashi, K., Hoson, T. and Kamisaka, S. (2001) Gravitational force regulates elongation growth of Arabidopsis hypocotyls by modifying xyloglucan metabolism. Adv. Space Res., 27, 1011-1016.

Soga, K., Wakabayashi, K., Kamisaka, S. and Hoson, T. (2002) Stimulation of elongation growth and xyloglucan breakdown in Arabidopsis hypocotyls under microgravity conditions in space. Planta, 215, 1040-1046.

Soga, K., Wakabayashi, K., Kamisaka, S. and Hoson, T. (2007) Effects of hypergravity on expression of XTH genes in azuki bean epicotyls. Physiol. Plant., 131, 332-340.

Tamaoki, D., Karahara, I., Schreiber, L., Wakasugi, T., Yamada, K. and Kamisaka, S. (2006) Effects of hypergravity conditions on elongation growth and lignin formation in the inflorescence stem of Arabidopsis thaliana. J. Plant Res., 119, 79-84. 